\title{
Measurement of air exchange rates in different indoor environments using continuous $\mathrm{CO}_{2}$ sensors
}

\author{
Yan You ${ }^{1,2}$, Can Niu ${ }^{1}$, Jian Zhou ${ }^{1}$, Yating Liu ${ }^{1}$, Zhipeng Bai ${ }^{1, *}$, \\ Jiefeng Zhang ${ }^{1}$, Fei $\mathrm{He}^{1}$, Nan Zhang ${ }^{1}$ \\ 1. State Environmental Protection Key Laboratory of Urban Ambient Air Particulate Matter Pollution Prevention and Control, College of \\ Environmental Sciences and Engineering, Nankai University, Tianjin 300071, China \\ 2. Research Center for Eco-Environmental Sciences, Chinese Academy of Sciences, Beijing 100085, China. E-mail: yanyou@rcees.ac.cn
}

Received 12 January 2011; revised 30 August 2011; accepted 10 September 2011

\begin{abstract}
A new air exchange rate (AER) monitoring method using continuous $\mathrm{CO}_{2}$ sensors was developed and validated through both laboratory experiments and field studies. Controlled laboratory simulation tests were conducted in a $1-\mathrm{m}^{3}$ environmental chamber at different AERs $\left(0.1-10.0 \mathrm{hr}^{-1}\right)$. AERs were determined using the decay method based on box model assumptions. Field tests were conducted in classrooms, dormitories, meeting rooms and apartments during 2-5 weekdays using $\mathrm{CO}_{2}$ sensors coupled with data loggers. Indoor temperature, relative humidity $(\mathrm{RH})$, and $\mathrm{CO}_{2}$ concentrations were continuously monitored while outdoor parameters combined with on-site climate conditions were recorded. Statistical results indicated that good laboratory performance was achieved: duplicate precision was within 10\%, and the measured AERs were 90\%-120\% of the real AERs. Average AERs were 1.22, 1.37, 1.10, 1.91 and $0.73 \mathrm{hr}^{-1}$ in dormitories, air-conditioned classrooms, classrooms with an air circulation cooling system, reading rooms, and meeting rooms, respectively. In an elderly particulate matter exposure study, all the homes had AER values ranging from 0.29 to $3.46 \mathrm{hr}^{-1}$ in fall, and 0.12 to $1.39 \mathrm{hr}^{-1}$ in winter with a median AER of 1.15 .
\end{abstract}

Key words: air exchange rate; continuous $\mathrm{CO}_{2}$ sensor; steady-state method; decay method; particulate matter; indoor-outdoor concentration relationship

DOI: $10.1016 / \mathrm{S} 1001-0742(11) 60812-7$

\section{Introduction}

In previous epidemiologic studies that reported the associations between exposure to outdoor/ambient air pollution and adverse health effects, onsite environmental monitoring data was used as the surrogate of the population's exposure levels to ambient air pollutants (Pope et al., 1995, 2002; Ballester F et al., 2001; de Hartog et al., 2003; IbaldMulli et al., 2004; Koenig et al., 2005; Strand et al., 2006; Miller et al., 2007; Ostro et al., 2007). However, most people, especially the most susceptible individuals, e.g., the elderly and children, spend the most time indoors (Abt et al., 2000; Kouniali et al., 2003; Bai et al., 2007), thus it is likely that a substantial fraction of exposure to outdoor air pollutants occurs while people stay indoors. Currently, however, it is not possible to measure the concentrations of indoor air pollutants from outdoor sources directly, making it difficult to accurately interpret the health risk estimates associated with outdoor/ambient air pollution found in numerous epidemiological studies.

To avoid misclassification of individual exposures and errors in the epidemiological analysis of pollution and

\footnotetext{
* Corresponding author. E-mail: zbai@ nankai.edu.cn
}

health data, many air pollution exposure studies have focused on the relationships between indoor/outdoor concentrations and personal exposure, most of which were obtained by a regression analysis of individual daily values of total personal exposure and indoor/outdoor concentrations (Abt et al., 2000; Wilson and Brauer, 2001; Weisel and Brauer, 2005). In these studies, measuring air exchange rates (AERs) was a crucial part because ventilation has the potential to transfer air pollutants generated outdoors to indoor environments, and also mitigate concentrations of indoor-generated air pollutants. Meanwhile, air exchange rates are important inputs to indoor air quality models, and indoor air models, in turn, are incorporated into the structure of total human exposure models (Pandian et al. 1993).

Many methods have been established to measure air exchange rates. Some studies reported AERs using perfluorocarbon tracer (PFT) compounds (Dietz et al., 1981, 1986; Leaderer et al., 1985; Cheong and Riffat, 1995). The most commonly used method is the sulfur hexafluoride $\left(\mathrm{SF}_{6}\right)$ decay test, which has been reported in many studies (McBride et al., 1997; Johnson et al., 2004) when commercial availability of instruments for $\mathrm{SF}_{6}$ tests has made AER 
measurements possible. However, the instrumentation for these methods is usually bulky and expensive. Measuring AERs in an effective, real-time, easy and low-cost way is still a challenge, especially in China where AER measurement techniques have not been usually applied.

Carbon dioxide $\left(\mathrm{CO}_{2}\right)$, although a ubiquitous compound in air, is also a bioeffluent. Occupants are usually the main indoor source of $\mathrm{CO}_{2}$, resulting in an increase of indoor $\mathrm{CO}_{2}$ concentrations compared with outdoor levels. $\mathrm{CO}_{2}$ can act as an indicator of ventilation efficiency, showing whether the supply of outside air is sufficient to dilute indoor air contaminants. As examples, to maintain odorfree environments with acceptable contaminant levels, China ventilation standards specify a $\mathrm{CO}_{2}$ ceiling of 800 ppm higher than outdoor levels. In this study, $\mathrm{CO}_{2}$ was employed as a tracer gas for determining AERs under certain circumstances satisfied for a box model. Commercially available $\mathrm{CO}_{2}$ sensors have the ability to measure real-time $\mathrm{CO}_{2}$ concentrations, and therefore semi real-time AERs can be determined using both steady-state and decay methods. The instruments are usually small in size, quiet, easy to use and relatively cheap. The objective of this study was to validate a method for measuring AERs using continuous $\mathrm{CO}_{2}$ sensors in both a controlled environmental chamber and real settings.

\section{Materials and methods}

\subsection{Box model for determining AERs}

A compartment with a simple and well-mixed interior zone, can be simplified as a box of specified volume. A box model can be established assuming that the inside air is fully mixed (Fig. 1). The carbon dioxide in a compartment is the result from outdoor concentrations and exhaled carbon dioxide.

The rate of change in concentration of the monitored gas depends on the concentration of the in-flowing air, the concentration of the out-flowing air and the internal generation rate of the gas.

For a contaminant of interest, the governing equation for this model is:

$V \mathrm{~d} C / \mathrm{d} t=Q_{\text {in }} C_{\text {in }}-Q_{\text {out }} C_{\text {out }}+S-k C$

i.e., $\mathrm{d} C / \mathrm{d} t=$ inflows - outflows + sources - degradation where, $V\left(\mathrm{~m}^{3}\right)$ is room volume, $C_{\text {in }}\left(\mathrm{mg} / \mathrm{m}^{3}\right), C\left(\mathrm{mg} / \mathrm{m}^{3}\right)$ and $C_{\text {out }}\left(\mathrm{mg} / \mathrm{m}^{3}\right)$ are concentrations of the monitored gas in the inflow, indoor air and outflow, respectively, $Q_{\text {in }}=Q_{\text {out }}=Q\left(\mathrm{~m}^{3} / \mathrm{hr}\right)$ are air flows into/out of the

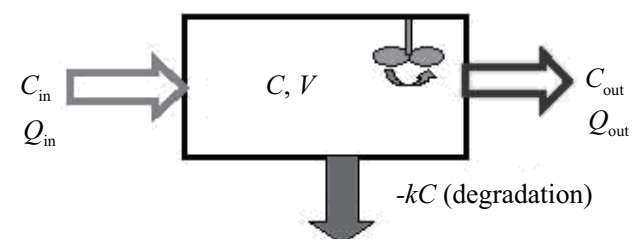

Fig. 1 Schematic diagram of a fully mixed box model. $C_{\text {in }}, C$ and $C_{\text {out }}$ are concentrations of the monitored gas in the inflow, indoor air and outflow, respectively, $Q_{\text {in }}, Q_{\text {out }}$ are air flows into/out of the building/space $V$ is room volume. building/space, $S(\mathrm{mg} / \mathrm{hr})$ is the indoor emission source of the monitored gas, and $k\left(\mathrm{~m}^{3} / \mathrm{hr}\right)$ is the first-order degradation constant.

Solving (Eq. (1)) by integration yields the final equation, which describes the generation and decay of the monitored gas as a function of time:

$C(t)=W /(\beta V)(1-\exp (-\beta t))+C_{0} \exp (-\beta t)$

where, $C_{0}(\mathrm{ppm})$ is concentration at $t=0, W=Q_{\text {in }} C_{\text {in }}+S$ and $B=\mathrm{AER}+k . C(t)(\mathrm{ppm})$ is the internal concentration of the monitored gas at time $t$.

For a conservative contaminant, i.e., $k=0$, AER can be determined in two ways:

(1) Steady-state method

When $t$ approaches infinity:

$\mathrm{AER}=W /(C V)$

(2) Decay method

When there is no source, i.e., $S=0$, AER can be resolved from the equation:

$C=Q C_{\text {in }} /(\beta V)[1-\exp (-\beta t)]+C_{0} \exp (-\beta t)$

\subsection{Environmental chamber simulation}

The laboratory simulation was evaluated in a simplified model chamber using a tracer gas technique, with $\mathrm{CO}_{2}$ gas injected into a supply duct. Ventilation systems, which consisted of an air supply pump, a $\mathrm{CO}_{2}$ gas generator, a $\mathrm{CO}_{2}$ gas analyzer and a small stainless steel environmental simulation chamber $(1 \mathrm{~m} \times 1 \mathrm{~m} \times 1 \mathrm{~m}, 1.5 \mathrm{~mm}$ thick walls), were set up to evaluate the performance of this box model for determining AER using $\mathrm{CO}_{2}$ concentrations for steady-state and decay processes. A fan was installed inside the chamber to provide the fully mixed condition. The $\mathrm{CO}_{2}$ level in the environmental chamber was measured at a height of $50 \mathrm{~cm}$ above the floor level using a Vaisala GMW20 series $\mathrm{CO}_{2}$ sensor (Vaisala Oyj, Helsinki, Finland). An air pump (Yinhu Company, China) was installed inside the chamber and emitted $\mathrm{CO}_{2}$ at a constant rate. One-channel data loggers equipped with temperature and relative humidity Hobo sensors (Hobo H08004-02, Onset Computer Corporation, USA) were used in conjunction with the $\mathrm{CO}_{2}$ sensor to capture the $\mathrm{CO}_{2}$ concentration every 10 seconds. Three were placed inside and one outside of the chamber to record ambient temperature and relative humidity simultaneously. Data from the data acquisition system were periodically downloaded via a cable to a PC for processing.

An air pump (Xinma Electronic Enterprise Co., Ltd., China) was installed at the downstream of the chamber to control the AERs. Duplicate simulations were performed at 10 AERs, i.e. $0.1,0.6,1.0,2.0,3.2,4.0,5.2,6.0$, 7.2 and $10.0 \mathrm{hr}^{-1}$, respectively. In each test, the chamber temperature and relative humidity were equilibrated with the room temperature at $20^{\circ} \mathrm{C}$ and $50 \%$, respectively. The $\mathrm{CO}_{2}$ pump was run for few minutes. Then the $\mathrm{CO}_{2}$ pump was shut down but the AER was kept constant.

Calibration of the $\mathrm{CO}_{2}$ sensors was accomplished weekly using zero gas $\left(\mathrm{N}_{2}\right.$, purity $\left.99.999 \%\right)$ and a series of 
carbon dioxide gas standards $(297,632,914,1212$, and $1501 \mathrm{ppm} \mathrm{CO}_{2}$ ). Instruments were also cross-compared during short-term (about $15 \mathrm{~min}$ ) outdoor air $\mathrm{CO}_{2}$ measurements at each outdoor location distant from potential $\mathrm{CO}_{2}$ sources. Calibration of the temperature and humidity sensors was performed by the manufacturer immediately prior to this research.

\subsection{Field tests on campus}

Field tests were conducted in four types of indoor environments (dormitory, classroom, reading room and meeting room) on campus during 2-5 weekdays. Previous research on $\mathrm{CO}_{2}$ in school classrooms (Fox et al., 2003) indicated a single monitoring location was appropriate for characterizing such indoor contaminant levels when HVAC systems were on, i.e., air was well-mixed. Considering probably inadequate full-mixing, 3 sets of equipment were placed in each classroom, reading room and meeting room for 12-48 $\mathrm{hr}$, approximately $1.5 \mathrm{~m}$ in height from the floor and $1.5 \mathrm{~m}$ away from windows, doors, fans, and occupants. One set of equipment was placed out of the windows about $1.5 \mathrm{~m}$ away from the surface of the buildings.

A walkthrough survey was completed for each location examining basic building characteristics, occupancy and other information potentially related to AERs. A daily journal was kept in detail to record the occupancy of each specific indoor environment (dormitories, classrooms, reading rooms and meeting rooms) and activities that might affect the air change rates, for example, when windows/doors were open or closed. Participants for dorm monitoring were asked to record their daily activities and location in a time-activities diary. Field technicians recalled and verified the entries of the diary at the end of field monitoring.

\subsection{Application in an elderly particulate exposure study in Tianjin}

The validated AER measurement method was applied in a study of elderly exposure to particulate matter with a mass median aerodynamic diameter $\leq 10 \mu \mathrm{m}\left(\mathrm{PM}_{10}\right)$ in Tianjin, China. A total of 80 elderly participants living in a residential community in the Dongli District of Tianjin were recruited for the $\mathrm{PM}_{10}$ exposure study. Field monitoring for each home was conducted over a 2-day period during fall and winter of 2009.

The 24-hr average indoor and outdoor $\mathrm{PM}_{10}$ mass concentrations were simultaneously monitored. Sampling pumps (Libra LP-20, VSS-5 and Elite-12, BUCK Corp., USA; BGI pump, BGI Inc., Waltham, USA) were used to collect $\mathrm{PM}_{10}$ at flow rates of $4 \mathrm{~L} / \mathrm{min}$. The impactor inlets were placed in the center of living rooms and out of windows about $1.5 \mathrm{~m}$ above the floor and at least $1.5 \mathrm{~m}$ away from the surface of the wall and furniture. The 37mm Teflon filters (2- $\mu \mathrm{m}$ pore; Pallflex Gelman Scientific, Ann Arbor, USA) for gravimetric mass concentration analysis were equilibrated before field sampling for at least 24 hr at $30 \%-40 \%$ relative humidity and $20-23^{\circ} \mathrm{C}$, and then were weighed twice on a Mettler MT5 (Mettler Toledo Inc., Columbus, USA) microbalance. After sampling, the
Teflon filters were equilibrated again and then weighed twice under the same conditions.

The AERs measurement set for each home included a $\mathrm{CO}_{2}$ sensor and a data logger with temperature and relative humidity sensors, and was placed $1.5 \mathrm{~m}$ high at the center of the living room. Data loggers were set to record the voltage values $\left(\mathrm{CO}_{2}\right.$ concentrations), temperature and relative humidity every $1.5 \mathrm{~min}$ during the 48-hr PM sampling period.

A time-activities diary concerning participant location, activities and duration was distributed to each participant at the beginning of indoor monitoring. Each participant completed the diary throughout the day. Field technicians visited 2-4 homes every $24 \mathrm{hr}$ between 08:00-09:00 to change filters, ensure correct functioning of pumps, adjust sampling flows, check the sampling inlet for possible leaks, download logger data, and collect diary information.

\section{Results}

\subsection{Laboratory simulation}

In the laboratory simulation, the air exchange rates of the environmental chamber were varied from 0.10-10.0 $\mathrm{hr}^{-1}$. Figure 2 gives an example of the data selection and data simulation in the decay method when the nominal air exchange rate was controlled at $1.0 \mathrm{hr}^{-1}$.
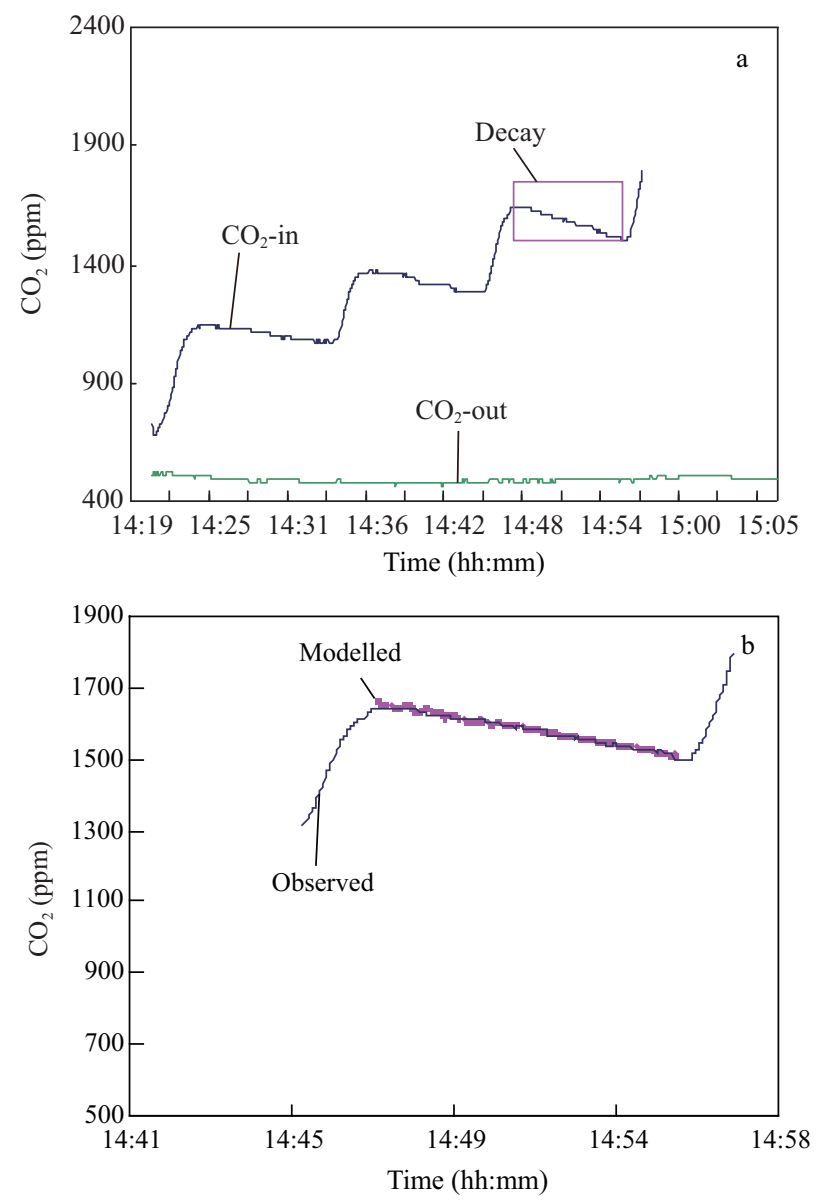

Fig. 2 (a) Decay curves of $\mathrm{CO}_{2}$ at $\mathrm{AER}=1.0 \mathrm{hr}^{-1}$ in the chamber on 30 June, (b) data simulation, $\mathrm{AER}_{\text {nominal }}=1.0 \mathrm{hr}^{-1}, \mathrm{AER}_{\text {simulation }}=1.06$ $\mathrm{hr}^{-1}$ (slope) on 30 June. 
Statistical results (Table 1) indicated that good laboratory performance was achieved: duplicate precision was within $10 \%$, differences between the steady-state and the decay methods were within $10 \%$, and the measured AERs were $90 \%-120 \%$ of the real AERs. Full mixing conditions were observed in the environmental chamber with fan operation.

Table 1 Simulated AERs and actual AERs using steady-state and decay methods

\begin{tabular}{lllll}
\hline \multirow{2}{*}{$\begin{array}{l}\text { Nominal } \\
\text { AERs } \\
\left(\mathrm{hr}^{-1}\right)\end{array}$} & \multicolumn{2}{c}{ Steady state method } & \multicolumn{2}{c}{ Decay method } \\
\cline { 2 - 5 } & $\begin{array}{l}\text { Simulated } \\
\text { AER }\left(\mathrm{hr}^{-1}\right)\end{array}$ & $\begin{array}{l}\text { Duplicate } \\
\text { precision }(\%)\end{array}$ & $\begin{array}{l}\text { Simulated } \\
\text { AER }\left(\mathrm{hr}^{-1}\right)\end{array}$ & $\begin{array}{l}\text { Duplicate } \\
\text { precision }(\%)\end{array}$ \\
\hline 0.10 & 0.12 & 9.2 & 0.11 & 9.2 \\
0.60 & 0.65 & 8.8 & 0.63 & 7.5 \\
1.0 & 1.2 & 4.7 & 1.1 & 3.3 \\
2.0 & 2.2 & 4.2 & 2.0 & 3.4 \\
3.2 & 3.5 & 3.9 & 3.3 & 3.1 \\
4.0 & 4.6 & 3.8 & 4.3 & 3.0 \\
5.2 & 5.6 & 2.8 & 5.7 & 2.0 \\
6.0 & 6.3 & 2.7 & 6.0 & 2.5 \\
7.2 & 7.9 & 2.5 & 7.6 & 2.5 \\
10.0 & 11.2 & 2.5 & 10.4 & 2.4 \\
\hline
\end{tabular}

\subsection{Air exchange rates in different indoor environments on campus}

\subsubsection{Indoor $\mathrm{CO}_{2}$ concentration, temperature, and rel- ative humidity on campus}

Table 2 presents descriptive statistics for indoor $\mathrm{CO}_{2}$ concentration levels, temperature, and relative humidity in different indoor environments on campus. Dormitories and reading rooms monitored were ventilated with ceiling fans with opened windows/doors. Meeting rooms were without any ventilation appliance other than air-conditioning. In former research, it was found that obtaining the required mixing of $\mathrm{CO}_{2}$ and air is often difficult. Multipoint injection of tracer gas into the airstream is frequently necessary and multipoint measurements from different locations within the airstream are essential to confirm mixing (Fisk and Faulkner, 1992). In the campus, because of high occupancy, indoor activities/movement of occupants, as well as the use of ceiling fans, adequate full-mixing was achieved. Indoor $\mathrm{CO}_{2}$ levels were similar within the same building (COVs $<20 \%$ ), indicating good mixing conditions.

Natural ventilation of buildings is the flow generated by temperature differences and by the wind. Although the wind may often appear to be the dominant driving mecha- nism, in many circumstances, temperature variations play a controlling role in ventilation (Linden, 1999). On the other hand, human comfort is a function of four major variables: air temperature, air movement, humidity, and the mean radiant temperature of interior surfaces. Occupants always opened windows and doors wide to increase their comfort because air movement increases heat transfer from the skin when cooler outside air exchanged with warm and humid indoor air. As a result, indoor and outdoor temperature difference, operation of ceiling fans, as well as occasional wind outdoors, worked together to force air to flow through windows and doors. No matter what the direction of the flow was, air exchange led to variations of indoor air temperature and relative humidity in turn.

The indoor $\mathrm{CO}_{2}$ concentration has also been used as a surrogate for the ventilation rate per occupant, including in schools (Lee and Chang, 1999). The American Society of Heating, Refrigeration, and Air-conditioning Engineers (ASHRAE, 2001) recommended that for adult office workers, assuming a ventilation rate of $7.5 \mathrm{~L} / \mathrm{sec}$ per person and a typical outdoor $\mathrm{CO}_{2}$ concentration of 350$400 \mathrm{ppm}$, a steady-state indoor $\mathrm{CO}_{2}$ concentration of 1000 ppm should be used as an informal dividing line between 'adequate' and 'inadequate' ventilation. It also specifies a minimum ventilation rate of $7.5 \mathrm{~L} / \mathrm{sec}\left(15 \mathrm{ft}^{3} / \mathrm{min}\right)$ per occupant for classrooms. In this study, almost half of the $\mathrm{CO}_{2}$ concentrations were above $1000 \mathrm{ppm}$. In classrooms and meeting rooms, over $80 \%$ were above 2000 ppm. If the measured $\mathrm{CO}_{2}$ concentrations had been maximum or steady-state values, a substantially larger proportion would be expected to exceed $1000 \mathrm{ppm}$. Thus, it was likely more than half of the rooms in campus study had ventilation rates less than specified in current minimum ventilation standards.

\subsubsection{Air exchange rates}

Based on the measured $\mathrm{CO}_{2}$ data, we computed the air exchange rates from the decay model using non-linear regression analysis to minimize squared residuals for selected periods when a smooth decay curve in $\mathrm{CO}_{2}$ levels was observed (Fig. 3a, b). The steady-state model was also applied in some cases but the steady state was not as often achieved as the decay state. Two to four such periods were analyzed for each room and results were averaged for every 24-hr period. In contrast to the traditional PFT method that always assumes that the ventilation does not vary over the measurement period and provides average indoor ventilation for a long-term period, AERs calculated from
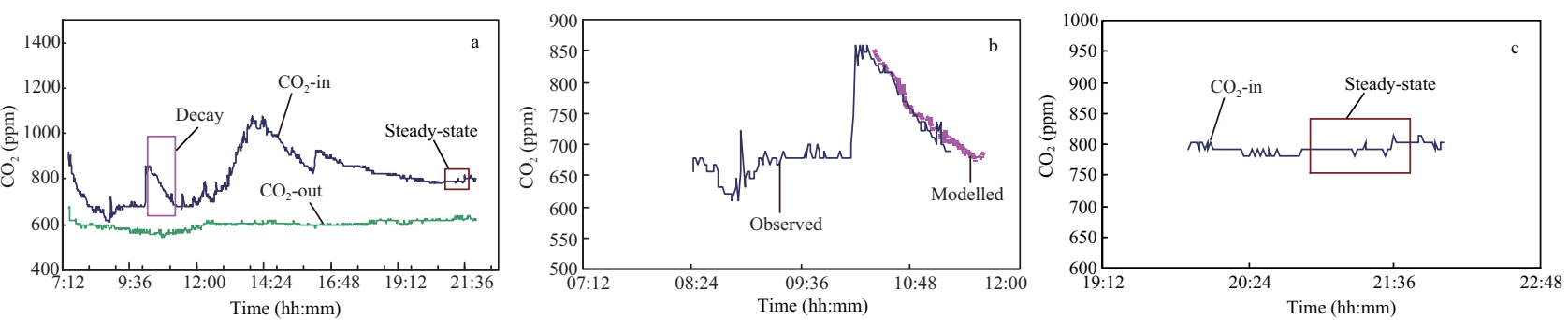

Fig. 3 (a) Indoor and outdoor $\mathrm{CO}_{2}$ concentrations of a dorm, and data selection for AERs calculation on 22 June, (b) simulation for selected data using the decay model, $\mathrm{AER}_{\text {simulation }}=0.82 \mathrm{hr}^{-1}$ on $22 \mathrm{June}$, (c) selected data for the steady-state model, $\mathrm{AER}_{\text {steady-state }}=1.82 \mathrm{hr}^{-1}$ on $22 \mathrm{June}$ 
Table 2 Indoor and outdoor $\mathrm{CO}_{2}$ concentrations, temperature and relative humidity on campus

\begin{tabular}{|c|c|c|c|c|c|c|}
\hline & \multicolumn{2}{|c|}{$\mathrm{CO}_{2}$ concentration $(\mathrm{ppm})$} & \multicolumn{2}{|c|}{ Temperature $\left({ }^{\circ} \mathrm{C}\right)$} & \multicolumn{2}{|c|}{ Relative humidity (\%) } \\
\hline & Average & Range & Average & Range & Average & Range \\
\hline Dorms & $1278 \pm 702$ & $612-2466$ & $26.8 \pm 5.4$ & $20.1-38.3$ & $68.1 \pm 17.8$ & $37.5-90.0$ \\
\hline Classroom & $2580 \pm 1854$ & $812-5346$ & $24.0 \pm 3.1$ & $20.1-30.4$ & $65.1 \pm 15.5$ & $38.6-76.5$ \\
\hline Reading rooms & $767 \pm 164$ & 629-994 & $22.1 \pm 3.9$ & $18.9-28.2$ & $60.2 \pm 19.4$ & $30.0-90.0$ \\
\hline Meeting rooms & $2394 \pm 1106$ & $762-3946$ & $23.5 \pm 2.7$ & $19.2-29.4$ & $60.4 \pm 14.3$ & $38.5-75.6$ \\
\hline Outdoor & $501 \pm 21$ & $478-534$ & $25.2 \pm 5.7$ & $18.0-39.0$ & $60.0 \pm 21.0$ & $35.0-90.0$ \\
\hline
\end{tabular}

the $\mathrm{CO}_{2}$ method represented the instantaneous ventilation for different short-term periods over the course of the measurement period (Fig. 3a).

\subsection{Application in an elderly particulate exposure study in Tianjin}

2.3.1 Indoor and outdoor $\mathrm{CO}_{2}$ concentration, temperature, and relative humidity in an elderly community

Table 4 presents descriptive statistics for indoor and outdoor carbon dioxide concentration levels, temperature, and relative humidity in an elderly community during fall and winter, 2009. Due to the low temperature and poor ambient air quality/ visibility (outdoor $\mathrm{PM}_{10}$ concentrations in winter in the community study ranged from 62.43 to 532.50 $\mu \mathrm{g} / \mathrm{m}^{3}$, and had an average of $218.14 \mu \mathrm{g} / \mathrm{m}^{3}$ ), most elderly did not keep windows open wide for long-time ventilation so that the indoor environment could stay warm and clean. As a result, indoor $\mathrm{CO}_{2}$ concentrations in winter were slightly higher than those in fall due to less ventilation, indicating lower air exchange rates in winter than those in fall.

\subsubsection{Air exchange rates}

With the variations of indoor and outdoor $\mathrm{CO}_{2}$, we usually captured 2-5 periods with a smooth decay curve or a steady-state curve (Fig. 4a) to calculate AER (Fig. 4b, c) for each apartment every day. Those AERs over $24 \mathrm{hr}$ were then averaged to obtain the daily AER for according apartment and $\mathrm{PM}_{10}$ monitoring data.

Figure 5 shows box plots of AER values for all the homes by season. The seasons were defined according to the calendar year 2009. The median AER was higher during the fall than that during the winter. All the homes had AER values ranging from 0.29 to $3.46 \mathrm{hr}^{-1}$ in fall, and 0.12 to $1.39 \mathrm{hr}^{-1}$ in winter. The homes had a median AER of $1.15 \mathrm{hr}^{-1}$ in fall and $0.54 \mathrm{hr}^{-1}$ in winter. During 2 day-long experiments in winter, although air exchange rates higher than $2 \mathrm{hr}^{-1}$ were sometimes achieved, the average over $24 \mathrm{hr}$ barely exceeded $1 \mathrm{hr}^{-1}$. This was considered to be due to the shorter ventilating time in winter (as judged by daily questionnaire data) than in fall. The Relationships of Indoor, Outdoor, and Personal Air (RIOPA) study found that during seasons when the indooroutdoor temperature difference was greater (and thus the
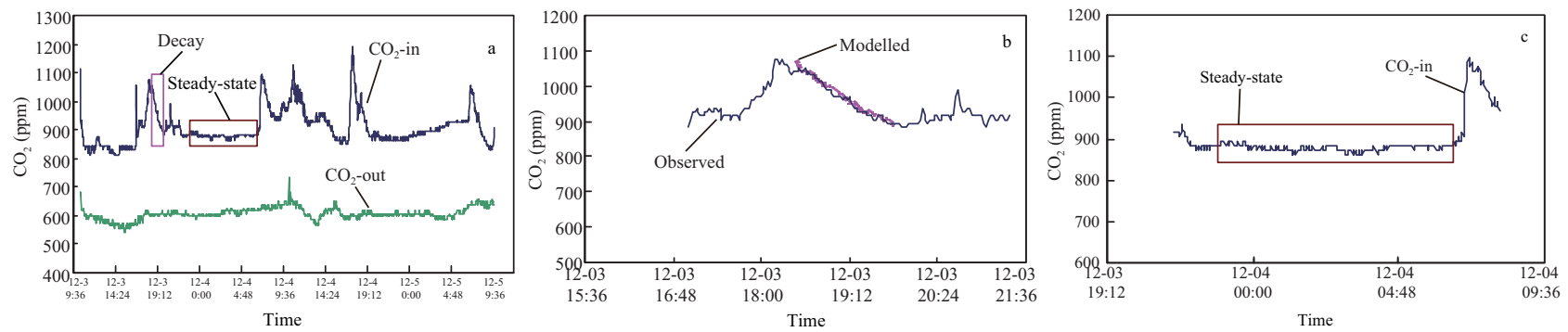

Fig. 4 (a) Indoor and outdoor $\mathrm{CO}_{2}$ concentration of an apartment, and data selection for AERs calculation, (b) simulation for selected data using the decay model, $\mathrm{AER}_{\text {simulation }}=0.37 \mathrm{hr}^{-1}$, (c) selected data for the steady-state model, $\mathrm{AER}_{\text {steady-state }}=0.90 \mathrm{hr}^{-1}$ in the year of 2009 .

Table 3 Air exchange rates in different indoor environments on campus

\begin{tabular}{lllll}
\hline & $\begin{array}{l}\text { Dorms } \\
(n=20)\end{array}$ & $\begin{array}{l}\text { Classroom I } \\
(n=10)\end{array}$ & $\begin{array}{l}\text { Classroom II } \\
(n=10)\end{array}$ & $\begin{array}{l}\text { Reading rooms } \\
(n=5)\end{array}$ \\
\hline Average & $1.22 \pm 0.67$ & $1.37 \pm 0.68$ & $1.10 \pm 0.55$ & $\begin{array}{l}\text { Meeting rooms } \\
(n=5)\end{array}$ \\
Range & $0.30-2.84$ & $0.68-2.30$ & $0.15-2.16$ & $0.73 \pm 0.48$ \\
& & $0.15-1.35$ & 0.87 \\
\hline
\end{tabular}

Classroom I: air-conditioned classrooms in an old building; classroom II: classrooms with an air circulation cooling system in a new building

Table 4 Indoor and outdoor $\mathrm{CO}_{2}$ concentration, temperature and relative humidity in an elderly community

\begin{tabular}{|c|c|c|c|c|c|c|c|}
\hline & & \multicolumn{2}{|c|}{$\mathrm{CO}_{2}$ concentration $(\mathrm{ppm})$} & \multicolumn{2}{|c|}{ Temperature $\left({ }^{\circ} \mathrm{C}\right)$} & \multicolumn{2}{|c|}{ Relative humidity (\%) } \\
\hline & & Average & Range & Average & Range & Average & Range \\
\hline \multirow[t]{2}{*}{ Fall } & Indoor & $738 \pm 188$ & $397-1385$ & $25.1 \pm 1.8$ & $20.9-28.7$ & $42.8 \pm 9.7$ & $23.5-67.2$ \\
\hline & Outdoor & $438 \pm 25$ & $364-723$ & $21.4 \pm 2.5$ & $4.2-33.6$ & $54.1 \pm 12.0$ & $23.5-100$ \\
\hline \multirow[t]{2}{*}{ Winter } & Indoor & $936 \pm 115$ & $378-2122$ & $20.6 \pm 0.55$ & $8.23-29.5$ & $27.1 \pm 3.2$ & $23.4-60.8$ \\
\hline & Outdoor & $551 \pm 27$ & $375-765$ & $2.1 \pm 1.9$ & $-4.8 \sim 7.9$ & $42.6 \pm 9.6$ & $23.4-73.5$ \\
\hline
\end{tabular}




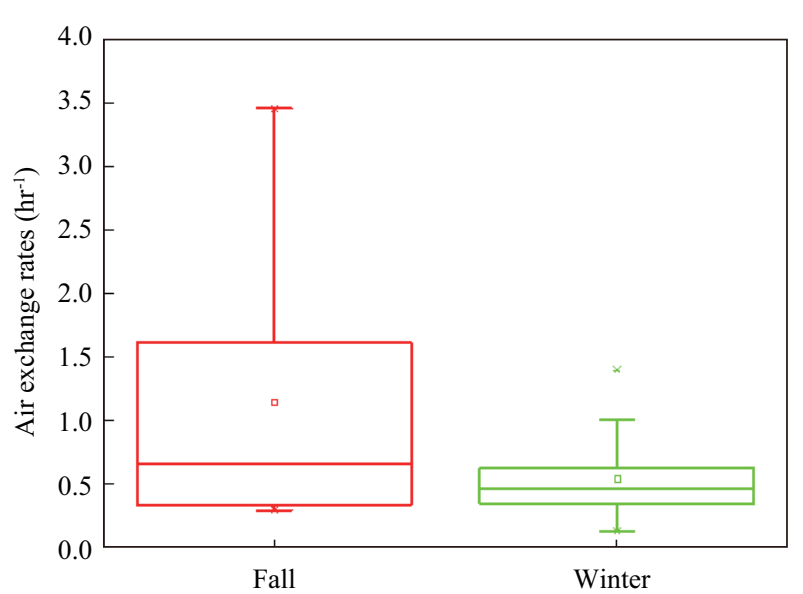

Fig. 5 Seasonal variations of AERs in an elderly community. The box plots summarize the mean, median, lower quartile, upper quartile, lower range, and upper range. Fall was defined as Aug 18 to Sepr 26; winter, Nov 15 to Dec 20.

infiltration and exfiltration by convection was greater), the median AER values tended to be greater, suggesting that convection may have been a dominating mechanism of air exchange for the homes (Weisel et al., 2005). In our study, residents shortened the ventilation time and also kept smaller opening areas of windows while the indooroutdoor temperature difference was greater in winter, so the convection was artificially reduced, and the median AER values tended to be lower.

\subsubsection{Ventilation and indoor-outdoor $\mathbf{P M}_{10}$ air concen- tration relationship}

Study-wide mean indoor and outdoor $\mathrm{PM}_{10}$ mass concentrations were 120.27 and $161.76 \mu \mathrm{g} / \mathrm{m}^{3}$ in fall, and 124.93 and $218.14 \mu \mathrm{g} / \mathrm{m}^{3}$ in winter, respectively (Fig. 6). No statistically significant difference was found between the indoor $\mathrm{PM}_{10}$ concentrations in fall (non-heating season) and in winter (heating season). Considering that indoor PM consists of (1) outdoor particles that have infiltrated indoors and remained suspended, (2) particles emitted indoors (primary) and (3) potentially, PM formed indoors

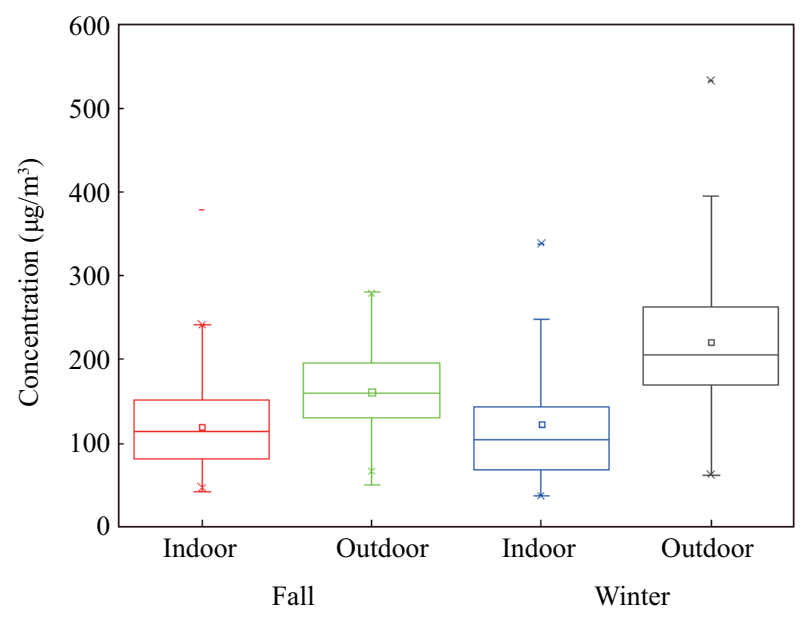

Fig. $6 \mathrm{PM}_{10}$ air concentrations for indoor-outdoor comparisons in fall and winter, 2009. The box plots summarize the mean, median, lower quartile, upper quartile, lower range, and upper range. through reactions with gas-phase precursors emitted both indoors and outdoors (secondary, e.g., low volatility products of ozone and alkenes) (Weschler and Shields, 1999), emission of outdoor sources might not contribute much to indoor particulate matter even in the heating season.

Previous studies also found that when indoor sources and indoor activities are present, indoor concentrations of PM can be substantially higher than outdoor concentrations (Weschler and Shields, 1999; Weisel et al., 2005). However, in this elderly community study, indoor $\mathrm{PM}_{10}$ concentrations were similar but significantly lower than outdoor concentrations both in fall (non-heating season) and in winter (heating season). A study conducted on two homes in the Boston metropolitan area (Abt et al., 2000) showed that indoor PM sources predominated when air exchange rates were $<1 \mathrm{hr}^{-1}$, and outdoor sources predominated when air exchange rates were $>2 \mathrm{hr}^{-1}$. Indoor PM sources were considered to be major contributors to indoor $\mathrm{PM}_{10}$ concentrations in the elderly PM exposure study with the AERs information. In the future, accurate contributions of specific indoor and outdoor PM emission sources will be apportioned with detailed PM chemical component data.

\section{Discussion}

\subsection{Limitations}

Recommended inhalation rates are summarized for adults, children, and outdoor workers/athletes by researchers in European countries and in the US, which is available for air contaminant exposure and health risk assessment studies for people in those areas (National Center for Environmental Assessment, 1997). However, inhalation rates have not been well characterized yet in China (Wang et al., 2009). Moreover, breathing rates and $\mathrm{CO}_{2}$ contents in exhaled air are influenced by weight, physical conditions, and specific activities and so on. This is not a problem during the unoccupied period, when the $\mathrm{CO}_{2}$ production rate is zero, but, in fact, it is difficult to get very accurate information about the rates of $\mathrm{CO}_{2}$ production within any space with limited information about inhalation rate exposure factors of Chinese residents, which may results in minor uncertainties in AERs estimation.

On the other hand, the semi real-time $\mathrm{CO}_{2}$ method is a kind of single-zone measurement technique. Single-zone measurement techniques have been extensively used in a wide variety of situations and by a large number of researchers. However, complex buildings whose interiors are not a simple, well-mixed zone cannot be easily described by a single-zone measurement method. Therefore different multizone measurement techniques have been developed to determine flows to and from multiple zones in buildings. However, multi-zone measurement techniques are not as attractive to use as the single-zone methods due to practical difficulties and uncertainties in the estimates (Sherman, 1997). In spite of the limitations discussed above, the semi real-time $\mathrm{CO}_{2}$ method is convenient, accurate, and lowcost for measuring AERs in various indoor environments. 


\subsection{Advantages and applications}

This method has been proven useful for microenvironments which may be treated as a single zone (e.g., residential apartments) and for isolatable sub-sections (e.g., classrooms) in complex buildings. The AERs measured in selected indoor environments in our study were comparable to those reported in literature. Average AERs were $1.22,1.37,1.10,1.91$ and $0.73 \mathrm{hr}^{-1}$ in dormitories, air-conditioned classrooms, classrooms with an air circulation cooling system, reading rooms, and meeting rooms, respectively. Homes in the elderly PM exposure study had an average AER of $1.15 \mathrm{hr}^{-1}$ in fall and $0.54 \mathrm{hr}^{-1}$ in winter. Indoor PM sources were considered to be the major contributor to indoor $\mathrm{PM}_{10}$ concentrations based on the AERs information.

Meanwhile, the method provided more detailed information about variations of ventilation with the help of real-time $\mathrm{CO}_{2}$ sensors. The most important assumption of PFT measurement techniques so far is that the ventilation does not vary over the measurement period. However, as we have found in our study, the ventilation was not actually constant over the measurement period ( $24 \mathrm{hr}$ or $48 \mathrm{hr}$ ). It has been shown that inconstant ventilation always leads to a negative bias in the estimation (Sherman 1989).

Air pollution is a major public health and environmental concern at present in China, especially in cities and areas with rapid economic development. More systematic research is still needed to disclose the characteristics of indoor air pollution, and characterize human exposure to various air pollutants and related health risk. For example, more details are needed about the transport of air pollutants between indoor and outdoor environments with variations of air exchange under controlled conditions. Considering high ambient air pollution concentration levels, especially in winter in north China, proper ventilation methods and strategies should be adopted to prevent the transport of outdoor air pollution into the indoor environment, mitigate air pollution emitted from indoor sources, and keep enough fresh air indoors at the same time.

\section{Acknowledgments}

This work was supported by the Scientific Research Projects for State Environmental Protection and Commonweal (No. 200709048), the National Natural Science Foundation of China (No. 20977054/B070704), the Innovation Fund of Nankai University, and Joint Research Grant to Both Nankai University and Tianjin University sponsored by the Ministry of Education, China.

\section{References}

Abt E, Suh H H, Allen G, Koutrakis P, 2000. Characterization of indoor particle sources: a study conducted in the metropolitan Boston area. Environmental Health Perspectives, 108(1): 35-44.

ASHRAE, 2001. Standard 62, Ventilation for Acceptable Indoor Air Quality, Atlanta, GA, American Society of Heating, Refrigerating, and Air Conditioning Engineers, Inc.
Bai Z, You Y, Gao X, Yu H, Yan L, Zhu T, 2007. Comparison of time-activity patterns in different periods in Tianjin, China. Epidemiology, 17(6): S454.

Ballester F, Tenías J M, Pérez-Hoyos S, 2001. Air pollution and emergency hospital admissions for cardiovascular diseases in Valencia, Spain. Journal of Epidemiology $\mathcal{E}$ Community Health, 55(1): 57-65.

Cheong K W, Riffat S B, 1995. New approach for measuring airflows in buildings using a perfluorocarbon tracer. Applied Energy, 51(3): 223-232.

de Hartog J J, Hoek G, Peters A, Timonen K L, Ibald-Mulli A, Brunekreef B et al., 2003. Effects of fine and ultrafine particles on cardiorespiratory symptoms in elderly subjects with coronary heart disease: the ULTRA study. American Journal of Epidemiology, 157(7): 613-623.

Dietz R N, Cote E A, Senum G I, Wieser R F, 1981. Inexpensive Perfluorocarbon Tracer Technique for Wide-scale Infiltration Measurements in Homes. BNL-30032, Upton, NY, Brookhaven National Laboratory.

Dietz R N, Goodrich R W, Cote E A, Wieser R F, 1986. Detailed description and performance of a passive perfluorocarbon transfer system for building ventilation and air exchange measurements. In: Measured Air Leakage of Buildings (Trechel H R, Laqus P L, eds.). ASTM STP 904, American Society of Testing and Materials, Philadelphia, PA. 203264.

Fisk W J, Faulkner D, 1992. Air exchange effectiveness in office buildings: measurement techniques and results. International Symposium on Room Air Convection and Ventilation Effectiveness, University of Tokyo.

Fox A, Harley W, Feigley C, Salzberg D, Sebastian A, Larsson $\mathrm{L}, 2003$. Increased levels of bacterial markers and $\mathrm{CO}_{2}$ in occupied school rooms. Journal of Environmental Monitoring, 5(2): 246-252.

Ibald-Mulli A, Timonen K L, Peters A, Heinrich J, Wölke G, Lanki T et al., 2004. Effects of particulate air pollution on blood pressure and heart rate in subjects with cardiovascular disease: a multicenter approach. Environmental Health Perspectives, 112(3): 369-377.

Johnson T, Myers J, Kelly T, Wisbith A, Ollisonc W, 2004. A pilot study using scripted ventilation conditions to identify key factors affecting indoor pollutant concentration and air exchange rate in a residence. Journal of Exposure Analysis and Environmental Epidemiology, 14(1): 1-22.

Koenig J Q, Mar T F, Allen R W, Jansen K, Lumley T, Sullivan $\mathrm{J} \mathrm{H}$ et al., 2005. Pulmonary effects of indoor- and outdoorgenerated particles in children with asthma. Environmental Health Perspectives, 113(4): 499-503.

Kouniali A, Cicolella A, Gonzalez-Flesca N, Dujardina R, Gehannob J F, Bois F Y, 2003. Environmental benzene exposure assessment for parent-child pairs in Rowen, France. Science of the Total Environment, 308(1-3): 73-82.

Leaderer B P, Schaap L, Dietz R N, 1985. Evaluation of the perfluorocarbon tracer technique for determining infiltration rates in residences. Environmental Science and Technology, 19(12): 1225-1232.

Lee S C, Chang M, 1999. Indoor air quality investigations at five classrooms. Indoor Air, 9(2): 134-138.

Linden P F, 1999. The fluid mechanics of natural ventilation. Annual Review of Fluid Mechanics, 31(1): 201-238.

McBride S J, Switzer P, Ott W, Hildemann L, Wien S, 1997. Preliminary results from an investigation of the differences between indoor air quality and personal exposures Air \& Waste Management Association, Pittsburgh, PA, 15222, 
USA. [np].

Miller K A, Siscovick D S, Sheppard L, Shepherd K, Sullivan J $\mathrm{H}$, Anderson G L et al., 2007. Long-term exposure to air pollution and incidence of cardiovascular events in women. The New England Journal of Medicine, 365(5): 447-458.

National Center for Environmental Assessment, 1997. Exposure Factors Handbook. US Environmental Protection Agency.

Ostro B, Feng W Y, Broadwin R, Green S, Lipsett M, 2007. The effects of components of fine particulate air pollution on mortality in california: Results from CALFINE. Environmental Health Perspectives, 115(1): 13-19.

Pandian M D, Ott W R, Behar J V, 1993. Residential air exchange rates for use in indoor air and exposure modeling studies. Journal Exposure and Analysis and Environmental Epidemiology, 3(4): 407-416.

Pope C A, Burnett R T, Thun M J, Calle E E, Krewski D, Ito $\mathrm{K}$ et al., 2002. Lung Cancer, Cardiopulmonary Mortality, and Long-Term Exposure to Fine Particulate Air Pollution. Journal of the American Medical Association, 287(9): $1132-1141$.

Pope C A, Thun M J, Namboodiri M M, Dockery D W, Evans J S, Speizer F E et al., 1995. Particulate air pollution as a predictor of mortality in a prospective study of U.S. adults. American Journal of Respiratory and Critical Care Medicine, 151(3): 669-674.

Sherman M H, 1989. Analysis of errors associated with passive ventilation measurement techniques. Building $\mathcal{E}$ Environment, 24(2): 131-139.

Sherman M H, 1997. Air Infiltration Measurement Techniques, Energy Performance of Buildings Group, Applied Science Division, Lawrence Berkeley Laboratory, University of California, Berkeley.

Strand M, Vedal S, Rodes C, Dutton S J, Gelfand E W, Rabinovitch N, 2006. Estimating effects of ambient $\mathrm{PM}_{2.5}$ exposure on health using $\mathrm{PM}_{2.5}$ component measurements and regression calibration. Journal of Exposure Science and Environmental Epidemiology, 16(1): 30-38.

Wang Z S, Wu T, Duan X L, Wang S, Zhang W J, Wu X F et al., 2009. Research on inhalation rate exposure factors of Chinese residents in environmental health risk assessment. Research of Environmental Sciences, 22(10): 1171-1175.

Weisel C P, Zhang J, Turpin B J, Morand M T, Colome S, Stock T H et al., 2005. Relationships of Indoor, Outdoor, and Personal Air (RIOPA). Part I, Collection Methods and Descriptive Analyses. 24.

Weschler C J, Shields H C, 1999. Indoor ozone/terpene reactions as a source of indoor particles. Atmospheric Environment, 33(15): 2301-2312.

Wilson W E, Brauer M, 2001. Methods to estimate the ambient and nonambient components of total personal exposure to particulate matter. Conference of the International Society of Exposure Assessment, Charleston, SC. 